\title{
CRÓNICA DEL SEMINARIO “DESAFÍOS DE LAS RELACIONES LABORALES ANTE LOS CAMBIOS TECNOLÓGICOS"
}

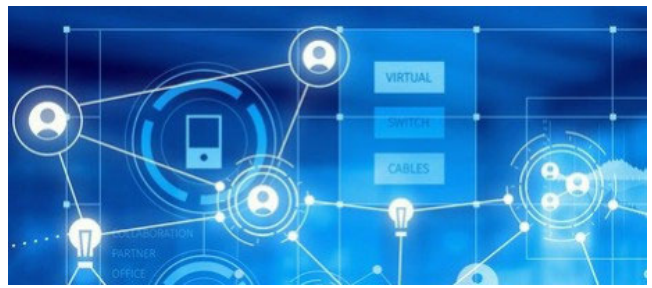

ROBERTO FERNÁNDEZ FERNÁNDEZ

Profesor Titular de Derecho del Trabajo y de la Seguridad Social RODRIGO TASCÓN LÓPEZ

Profesor Titular de Derecho del Trabajo y de la Seguridad Social

HENAR ÁLVAREZ CUESTA

Profesor Titular de Derecho del Trabajo y de la Seguridad Social

Universidad de León

El día 20 de noviembre de 2018 se celebró en el Salón de Grados de las Facultades de Derecho/Ciencias del Trabajo el Seminario "Desafíos de las Relaciones Laborales ante los cambios tecnológicos", enmarcado en los Proyectos de Investigación DER2017-82192-C3-1R "Nuevos lugares, distintos tiempos y modos diversos de trabajar", del que son Investigadores Responsables los Dres. Juan José Fernández Domíguez y Roberto Fernández Fernández, y LE004P17 "Sostenibilidad económica, social y medioambiental e innovación tecnológica: nuevas coordenadas para las políticas públicas en Castilla y León", del que es investigadora principal la Dra. Susana Rodríguez Escanciano. Asimismo, la actividad estaba asociada al Programa de Doctorado "Derecho: protección jurídica y cohesión social".

1ª Ponencia: "Relaciones Laborales y cambios tecnológicos: ¿Cómo se protege el derecho a la protección de datos de los trabajadores"

Fue ponente la Dra. Eva Ma Blázquez Agudo, Profesora Titular de Derecho del Trabajo y de la Seguridad Social de la Universidad Carlos III de Madrid, actuando como relator el Profesor Rodrigo Tascón López, Profesor Titular de la Universidad de León. 
La ponente dio cuenta de la evolución normativa acaecida en los últimos tiempos en materia de protección de datos, desde el REGLAMENTO (UE) 2016/679 DEL PARLAMENTO EUROPEO Y DEL CONSEJO, de 27 de abril de 2016, relativo a la protección de las personas físicas en lo que respecta al tratamiento de datos personales y a la libre circulación de estos datos y por el que se deroga la Directiva 95/46/CE (Reglamento general de protección de datos); hasta la nueva Ley Orgánica de Protección de Datos y Economía Digital, en última fase tramitación parlamentaria.

A continuación, procedió a desgranar la problemática concreta que la protección de datos presenta en el ámbito laboral, para recordar que la propia firma del contrato de trabajo es título habilitante suficiente para permitir al empresario el tratamiento de los datos necesarios para el desarrollo normal de la relación laboral, incluido el siempre espinoso asunto del control a través de medios tecnológicos, sobre el que ha habido una larga saga de pronunciamientos de los tribunales de todo orden y condición, destacando la ponente las últimas sentencias del Tribunal Europeo de Derechos Humanos, en los asuntos Barbulescu II y López Ribalda, en las que se parece enmendar un poco la plana a la interpretación menos tuitiva de los derechos de los trabajadores que había efectuado el Tribunal Constitucional Español.

Advirtió además la ponente que entre los datos laborales hay algunos especialmente sensibles, como son los datos de salud laboral o afiliación sindical, que deben ser tratados con especial esmero y sólo cuando una Ley lo permita, so pena de incurrir en lesión del derecho fundamental consagrado en el art. 18.4 CE.

Aludió, en fin, a la necesidad de que las políticas y protocolos establecidos a nivel de empresa, con el debido acuerdo con los representantes de los trabajadores, deben resultar claves para asegurar un adecuado desenvolvimiento del derecho a la protección de datos en el ámbito laboral, así como para tratar de alejar, en lo posible, el fantasma de las diversas responsabilidades en que se puede incurrir.

$2^{a}$ Ponencia: "Algunas propuestas de reforma en materia de tiempo de trabajo. En especial en relación con la conciliación laboral y familiar"

Fue ponente el Prof. Dr. Juan Altés Tárrega, Profesor TU de Derecho del Trabajo y de la Seguridad Social de la Universidad de Valencia, actuando como relatora la Profra. Dra. Henar Álvarez Cuesta, Profesora TU de Derecho del Trabajo y de la Seguridad Social de la Universidad de León.

Durante su intervención, el Prof. Altés Tárrega examinó el marco normativo del tiempo de trabajo a nivel nacional y europeo, su interpretación judicial, analizó el impacto que la digitalización supone para esta condición laboral, la modalidad específica del contrato a tiempo parcial e intercaló propuestas de mejora para propiciar una corresponsabilidad y evitar la discriminación por razón de género.

Al respecto, comparó los intereses contrapuestos de trabajador y empresario con un "damero maldito", en tanto responden a distintas lógicas y voluntades. De un lado, la 
flexibilidad pasiva en su distribución beneficia al empleador, mientras que los empleados reivindican una flexibilidad segura que les permita ejercer sus derechos de conciliación.

Al tiempo, subrayó cómo esta vital condición laboral ha sido distorsionada por las nuevas tecnologías, capaces de difuminar la separación entre tiempo de trabajo y tiempo de descanso, al permitir las nuevas tecnologías jornadas más flexibles. Frente al cambio de paradigma, se ha incluido el derecho a la desconexión digital en el Proyecto de Ley de Protección de Datos, como protección específica frente a un incumplimiento empresarial específico.

Respecto al contrato a tiempo parcial, el ponente apuntó las dificultades para que esta modalidad específica cumpla con una de sus finalidades, como es facilitar la conciliación. La flexibilidad empresarial fruto de las últimas reformas sumada a la incorporación "forzada" debido a la escasa oferta laboral hace que no sirva a quienes acudirían a este vínculo para compaginar cuidados y trabajo.

Por último, el Prof. Altés dibujó los dos caminos abiertos de reforma de las instituciones destinadas a conciliar la vida personal, laboral y familiar. El primero consistiría en efectuar ajustes legales para atender a demandas sociales, como establecer el derecho de acumulación del permiso de lactancia, la inclusión del cónyuge en la excedencia por cuidado de familiares y eliminación de la afinidad para evitar la asignación de los cuidados en exclusiva a la mujer, la supresión del parámetro diario en las posibilidades de reducción de jornada por estas causas o la necesaria justificación del empresario a la solicitud de medidas de conciliación por parte del trabajador.

El segundo llevaría a romper con todo y volver a empezar en el diseño de la corresponsabilidad familiar con el fin de luchar contra la discriminación indirecta que sigue recayendo sobre las mujeres y acaba por segregarlas ocupacionalmente y ampliar la brecha salarial y de pensiones. En este punto, señala la necesaria intervención en tres momentos: en la gestión del tiempo de trabajo en aspectos cualitativos para evitar la pérdida salarial; en el establecimiento de permisos parentales igualitarios mediante una estructura en parte fija y en parte flexible vinculada a su disfrute equivalente entre ambos progenitores; y en el desligamiento del tiempo de postparto de la suspensión por maternidad para su consideración como incapacidad temporal.

En fin, y como conclusión, es necesario no solo un cambio legal y convencional, sino también un cambio de mentalidad en empresas, trabajadores y sociedad en su conjunto si se pretende alcanzar la verdadera corresponsabilidad familiar. 
$3^{a}$ Ponencia: "Impacto de la economía de las plataformas en la relación individual"

Fue ponente la Dra. Patricia Nieto Rojas, Profesora Ayudante Doctor de Derecho del Trabajo y de la Seguridad Social de la Universidad Carlos III de Madrid, actuando como relator el Profesor Roberto Fernández Fernández, Profesor Titular de Universidad de Derecho del Trabajo y de la Seguridad Social de la Universidad de León.

La ponente comienza dando cuenta de la importancia cualitativa que la economía a través de plataformas presenta para el Derecho del Trabajo y de la Seguridad Social, pues pone en duda la manera de interpretar los presupuestos clásicos de un contrato de trabajo, difuminando la prestación de servicios a través de las mismas dos variables fundamentales como son el tiempo y el lugar de trabajo.

A su juicio es necesario diferenciar entre el consumo colaborativo, que produce unos intereses comunes para los consumidores pero cuyo objetivo fundamental no es llegar a generar ánimo de lucro, de la economía de las plataformas que dan lugar a trabajos de alto valor añadido y que actúan en sectores tradicionales y que, por tanto, sí generan unos beneficios para quienes actúan bajo su paraguas, resultando dudoso que quienes prestan servicios para estas plataformas no deban ser considerados como trabajadores por cuenta ajena.

La ponente señala que la economía de plataformas presenta entre sus ventajas una mejora de la vida de los consumidores, les da acceso a una mayor oferta y les permite una mayor capacidad de elección informada.

Sin embargo, entre sus desventajas da cuenta de un empeoramiento de las condiciones de las personas que prestan servicios en las mismas, al no ser considerados por las plataformas como trabajadores por cuenta ajena; genera una competencia desleal para los operadores tradicionales que tienen que cumplir unos estándares mínimos legales, cuando lo que les diferencia no es la actividad desarrollada sino la herramienta que utilizan para llevarla a cabo; puede generar monopolios expulsando a los operadores tradicionales; elimina a las personas no informatizadas que no podrán acceder a sus servicios o, por no seguir, puede provocar un mayor control a los usuarios por parte de las plataformas a la hora de "manipular" los big data.

De esta manera, el Derecho del Trabajo tiene que hacer frente a una nueva realidad en la cual "se digitaliza lo físico" y se utilizan nuevas herramientas para hacer frente a las necesidades productivas de sectores tradicionales, asistiendo a una fragmentación y marginalización del trabajo, pues se exige la disponibilidad durante determinados períodos de tiempo sin saber si va a tener o no tareas, y se ofertan microtareas, de manera que los prestadores compiten por un trabajo cada vez más precario.

Frente a esta situación, para la ponente, el Derecho del Trabajo debe plantearse como regular la economía de las plataformas y, a su juicio, ordenar las condiciones laborales 
de quienes prestan servicios en las mismas, pues para ella se trata de trabajadores por cuenta ajena, a los que se aplica la normativa laboral común.

Según su parecer, concurren indicios de dependencia, aun cuando la misma se atenúe por las peculiaridades del desempeño desarrollado, en tanto en cuanto los prestadores son personas físicas, se necesita una autorización de la plataforma para poder operar, el coste del servicio y la comisión son prefijados por ella, el cliente abona el pago del servicio a la plataforma y esta lo hace llegar al prestador, existe la posibilidad de que la plataforma "desactive" al prestador cuando este disminuye su nivel de reputación, los prestadores no pueden elegir el horario y no son totalmente libres de aceptar los servicios pues si los recahazan bajan en su calificación $\mathrm{y}$, por no seguir, deben asumir unas guías de buenas prácticas que se parecen mucho a órdenes empresariales.

Eso sí, no desconoce las dificultades de dicha categorización, como lo demuestran las sentencias contradictorias sobre Deliveroo y Glovo de Juzgados de lo Social de Valencia y Madrid, y señala que si no resulta posible la laboralización de estas actividades, resultará necesario avanzar hacia un derecho de la actividad profesional, de manera que se reconozcan determinados derechos laborales a estos trabajadores autónomos.

En conclusión, sea como trabajadores por cuenta ajena o como trabajadores por cuenta propia resulta necesario el reconocimiento de una serie de derechos capaces de regular sus condiciones laborales, marcando así unos estándares mínimos que les permita acceder a una prestación de servicios decente. 